\title{
Influência da aplicação de irradiação por feixe de elétrons na qualidade microbiológica de filés de corvina (Micropogonias furnieri) refrigerados
}

\author{
[Influence of irradiation application for electron beam on the microbiological \\ quality of chilled croaker (Micropogonias furnieri) fillets] \\ C.C.C. Barcellos ${ }^{1}$, A.B.M. Fonseca ${ }^{2}$, M.C.L. Souza ${ }^{3}$, R.M. Franco ${ }^{4}$, E.F.M. Mesquita ${ }^{4}$ \\ ${ }^{1}$ Instituto de Biologia do Exército (IBEx) - Faculdade de Veterinária - Universidade Federal Fluminense, RJ \\ ${ }^{2}$ Instituto de Matemática e Estatística - Universidade Federal Fluminense, RJ \\ ${ }^{3}$ Universidade Estadual da Zona Oeste - Uezo, RJ \\ ${ }^{4}$ Faculdade de Veterinária - UFF - Universidade Federal Fluminense, RJ
}

\begin{abstract}
RESUMO
A adequada manipulação do pescado desde sua captura até seu processamento tecnológico, além da manutenção das condições higiênico-sanitárias, o que inclui a qualidade da água utilizada na cadeia, influencia na carga microbiana inicial apresentada. A fim de retardar o processo de deterioração, diminuir as perdas e os riscos iminentes à saúde coletiva, como a propagação de agentes etiológicos de doenças alimentares, são empregados diferentes métodos de conservação. Os feixes de elétrons são utilizados em vários países e levam à destruição dos microrganismos por alterações em suas estruturas, as quais ocorrem pela remoção de elétrons de seus átomos. Objetivou-se, no presente trabalho, contribuir para a avaliação da eficiência da irradiação por feixe de elétrons na qualidade microbiológica de filés de corvina (M. furnieri) refrigerados, desembarcados no município de Niterói - RJ, Brasil. Foram realizadas contagem de bactérias heterotróficas aeróbias mesófilas, de bactérias heterotróficas aeróbias psicrotróficas e enumeração de Enterococcus spp. e, posteriormente, comparadas as amostras do grupo controle com as dos grupos irradiados a doses de 0,7 e 1,0kGy. Os peixes inteiros foram adquiridos no cais de Itaipu, filetados no mercado, embalados a vácuo e mantidos a $\pm 4^{\circ} \mathrm{C}$. Embora não tenha sido encontrada diferença estatisticamente significativa entre os três grupos $(\mathrm{P}>0,05)$ em nenhuma das análises, concluiu-se que o processamento utilizado foi eficaz na redução do crescimento das três bactérias pesquisadas no dia zero de ambos os grupos irradiados.
\end{abstract}

Palavras-chave: irradiação de alimentos, Micropogonias furnieri, pescado, qualidade microbiológica

\begin{abstract}
The proper handling of fish from capture to technological processing, as well as maintenance of sanitary conditions and the quality of water, can influence the initial microbial load presented. In order to slow down the deterioration process, the reduction of losses and eminent risk to public health as the spread of etiological agents of foodborne illness are different methods used for storage. Electron beams are used in several countries and lead to the destruction of microorganisms by changes in their structures, which occur by removing electrons from their atoms. The objective in the present study contributes to the evaluation of electron beam irradiation efficiency in microbiological quality of chilled croaker fillets (M. furnieri), landed in Niterói - RJ, Brazil. Were performed Bacteria Count Heterotrophic aerobic mesophilic, psychrotrophic bacteria Heterotrophic Aerobic and enumeration of Enterococcus spp. and subsequently compared to the control group of samples with the groups irradiated at doses of 0.7 and $1.0 \mathrm{kGy}$. Whole fish were purchased from the Itaipu pier, threaded on the market, vacuum packed and kept at $\pm 4^{\circ} \mathrm{C}$. Although there was no statistically significant difference among the three groups $(P>0.05)$ in any of the analyzes, it was concluded that the application of this technology was effective in reducing the growth of the three bacteria surveyed on day zero of both irradiated groups.
\end{abstract}

Keywords: food irradiation, Micropogonias furnieri, fisheries, microbiological quality

Recebido em 26 de abril de 2015

Aceito em 15 de novembro de 2015

E-mail: carolinacbarcellos@hotmail.com 


\section{INTRODUÇÃO}

\begin{abstract}
A corvina (Micropogonias furnieri) (perciformes: Sciaenidae) teve sua espécie descrita originalmente por Desmarest em 1823. É um pescado importante e normalmente comercializado fresco ou salgado (Fao, 2013). Constitui uma das principais espécies capturadas no município de Niterói/RJ (Fiperj, 2011).
\end{abstract}

No pescado, a decomposição se inicia rapidamente, poucos instantes após sua morte, devido à presença de microrganismos oriundos do ambiente onde vivem, seja ele marinho ou fluvial, os quais, em sua maioria, não são patogênicos para o homem. Porém, em caso de águas poluídas por esgotos e manipulação inadequada, há maior possibilidade de ocorrência de agentes etiológicos de doenças alimentares (Riedel, 2005).

Todas as bactérias patogênicas veiculadas por alimentos são mesófilas. A contagem de bactérias heterotróficas aeróbias mesófilas (CBHAM) em placas é normalmente utilizada para se avaliarem as condições sanitárias do produto alimentício. Ainda que não sejam encontrados microrganismos patogênicos ou alterações sensoriais, altas contagens bacterianas em alimentos não fermentados podem causar danos à saúde coletiva (Franco e Landgraf, 2008).

Já os organismos psicrotróficos são aqueles capazes de se desenvolver em temperaturas entre $0^{\circ} \mathrm{C}$ e $7^{\circ} \mathrm{C}$ (Jay, 2005). A decomposição gerada pela presença de bactérias heterotróficas aeróbias psicrotróficas nos alimentos se justifica em especial pela capacidade que possuem de produzir proteases, lipases e fosfolipases (ICMSF, 1986).

Os Enterococcus spp., quando em grande quantidade em um alimento, desde que não pertençam à sua composição, demonstram problemas nas condições sanitárias ou de acondicionamento (Franco e Landgraf, 2008). A relevância do estudo desses microrganismos em produtos alimentícios se deve à possível resistência a agentes antimicrobianos, elevando as chances do aparecimento de casos de agentes etiológicos veiculados por alimentos e de infecções hospitalares (Giraffa et al., 2000).
A fim de controlar o desenvolvimento desses e de outros microrganismos, o emprego dos métodos de conservação deve ser feito o mais prontamente possível, retardando a instalação da deterioração e mantendo o produto fresco por um período maior. Uma das formas de conservação utilizadas para aumentar a validade comercial de alimentos é a aplicação de radiações ionizantes, devido a sua ação na eliminação de microrganismos e na inibição de alterações bioquímicas. Uma das formas de radiação utilizada em alimentos são os feixes de elétrons, que possuem como benefício a capacidade de direcionamento dos feixes, garantindo uma aplicação homogênea (Fellows, 2006).

Objetivou-se neste estudo, por meio da contagem de bactérias heterotróficas aeróbias mesófilas, de bactérias heterotróficas aeróbias psicrotróficas e do número mais provável de Enterococcus spp., contribuir para a avaliação da interferência da aplicação de irradiação por feixe de elétrons na qualidade microbiológica de filés de corvina refrigerados e desembarcados no município de Niterói, Rio de Janeiro, Brasil.

\section{MATERIAL E MÉTODOS}

As corvinas foram adquiridas diretamente no cais de Itaipu, Niterói, Rio de Janeiro, onde ocorre o desembarque da pesca artesanal, e transportadas em caixa isotérmica contendo gelo, garantindo que fosse preservada a temperatura de refrigeração até o mercado de peixe, localizado no centro do município, onde foram filetadas. Os filés foram pesados, acondicionados em envelopes de polietileno (cada um com 100g) e transportados para a UFF, para serem embalados a vácuo, e as embalagens devidamente vedadas.

Em seguida, todas as 30 amostras, oriundas de 15 animais, foram novamente acondicionadas $\mathrm{e}$ transportadas para a empresa Acelétron, situada no Irajá, Rio de Janeiro, local onde 20 foram irradiadas, por meio da utilização de feixe de elétrons. Dez amostras receberam a dose de $0,7 \mathrm{kGy}$ e outras dez, de $1,0 \mathrm{kGy}$, ficando o restante, pertencente ao grupo controle, no interior da caixa isotérmica.

Após serem irradiadas, as amostras foram devolvidas para o recipiente, para então retornarem à UFF, onde ficaram armazenadas em geladeira a $\pm 4^{\circ} \mathrm{C}$, até o final do experimento, e 
onde foram realizadas as análises bacteriológicas: contagem de bactérias heterotróficas aeróbias mesófilas (CBHAM), contagem de bactérias heterotróficas aeróbias psicotróficas (CBHAP) e número mais provável (NMP) de Enterococcus spp. Tais análises foram realizadas sem repetições. As metodologias empregadas foram baseadas nas respectivas técnicas inseridas no "Compendium of Methods for the Microbiological Examination of Foods", para CBHAM e CBHAP, segundo Downes e Ito (2001), e no "Microbiology Manual Merck", descrito por Merck (1996), para número mais provável de Enterococcus spp. Para análise dos resultados foram utilizadas estatística não paramétrica e estatística descritiva. Para análise não paramétrica foi empregado $\mathrm{o}$ teste de Kruskal-Wallis, com significância de 5\%. A estatística descritiva foi utilizada para descrever o desenvolvimento dos grupos bacterianos avaliados ao longo do tempo.

\section{RESULTADOS E DISCUSSÃO}

Conforme a legislação brasileira vigente, exposta em Brasil (2001), não são estabelecidos limites máximos para CBHAM e CBHAP, utilizando-se, assim, como referência a ICMSF (1986), que exibe o limite de $10^{7} \mathrm{UFC} / \mathrm{g}$.

Após avaliação das contagens de bactérias heterotróficas aeróbias mesófilas e das contagens de bactérias heterotróficas aeróbias psicrotróficas encontradas nas amostras de cada um dos três grupos estudados, observou-se que não houve diferença estatisticamente significativa entre os grupos, $\mathrm{P}=0,259$ e $\mathrm{P}=0,808$, respectivamente.

Mesmo as CBHAM e as CBHAP encontrando-se altas desde as primeiras análises, somente no quarto dia, pela primeira vez, foi transcendido o limite estipulado pela legislação, apresentando o grupo controle na CBHAM o valor de 1,5 x $10^{7} \mathrm{UFC} / \mathrm{g}$, e a partir do $10^{\circ}$ dia, o valor de $6,9 \mathrm{x}$ $10^{8} \mathrm{UFC} / \mathrm{g}$ na CBHAP.

Já o grupo irradiado a 0,7 só se encontrou fora dos padrões a partir do $14^{\circ}$ dia em relação à CBHAM, com $8,4 \times 10^{7} \mathrm{UFC} / \mathrm{g}$ e, pela primeira vez, no sétimo dia, em relação à CBHAP, com $1,5 \times 10^{7} \mathrm{UFC} / \mathrm{g}$.

Quanto às amostras irradiadas a 1,0kGy, somente no $10^{\circ}$ dia, pela primeira vez, foi transcendido o limite estipulado pela legislação, sendo a CBHAM de $1,8 \times 10^{7} \mathrm{UFC} / \mathrm{g}$, e a CBHAP, a partir desse mesmo dia, de $1,9 \times 10^{7} \mathrm{UFC} / \mathrm{g}$.

Por conseguinte, verificou-se que a irradiação por feixe de elétrons, de certa forma, foi eficiente na redução da CBHAM e também da CBHAP, tanto em relação à redução encontrada no dia zero, quando comparadas as contagens do grupo controle com as dos irradiados a ambas as doses, sendo a diminuição das bactérias mesófilas mais aparente do que a das psicrotróficas, quanto em relação ao dia em que as amostras irradiadas começaram a transcender o padrão preconizado.

Ao serem comparadas as linhas de crescimento dos grupos estudados, levando em consideração a CBHAM, o grupo controle merece destaque devido a um pico apresentado do dia sete ao dia 10, destoando dos demais, sendo a maior contagem $2,7 \times 10^{8} \mathrm{UFC} / \mathrm{g}$, seguido por um abrupto declínio até o $14^{\circ}$ dia. O crescimento segue progressivo até o $24^{\circ}$ dia e termina apresentando uma evidente redução, estabelecida entre o $24^{\circ}$ e o $30^{\circ}$ dia. Quanto às linhas dos dois grupos irradiados, quando comparadas entre si, observou-se um crescimento mais semelhante, no entanto, contagens mais altas foram identificadas no grupo irradiado a $0,7 \mathrm{kGy}$. De forma geral, os valores mínimo e máximo encontrados para as amostras irradiadas a 0,7 foram de 7,0 x $10^{3} \mathrm{UFC} / \mathrm{g}$ no segundo dia e de $1,2 \times 10^{8} \mathrm{UFC} / \mathrm{g}$ nos dias 24 e 30 , o que pode caracterizar o início da fase estacionária do crescimento bacteriano. Nas irradiadas a 1,0kGy, os valores extremos foram $1,5 \times 10^{4} \mathrm{UFC} / \mathrm{g}$, também no segundo dia, e $9,1 \times 10^{7} \mathrm{UFC} / \mathrm{g}$ no $17^{\circ}$, apresentando do $24^{\circ}$ ao $30^{\circ}$ diminuição na contagem (Fig. 1).

No que se refere à CBHAM, conforme ilustrado na Fig. 2, observou-se que as amostras possuíam contagens que variaram de $7,0 \times 10^{3}$ e de $2,7 \times$ $10^{8} \mathrm{UFC} / \mathrm{g}$, ficando a média em 4,6 x $10^{7} \mathrm{UFC} / \mathrm{g}$, desvio-padrão de $6,3 \times 10^{7} \mathrm{UFC} / \mathrm{g}$ e mediana de $1,65 \times 10^{7} \mathrm{UFC} / \mathrm{g}$. 


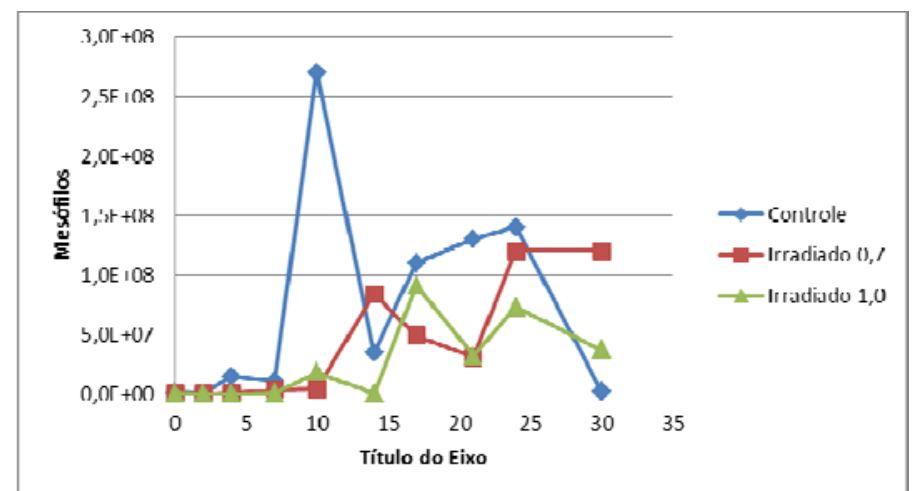

Figura 1. Gráfico em linha comparando a CBHAM em UFC/g dos três grupos analisados.

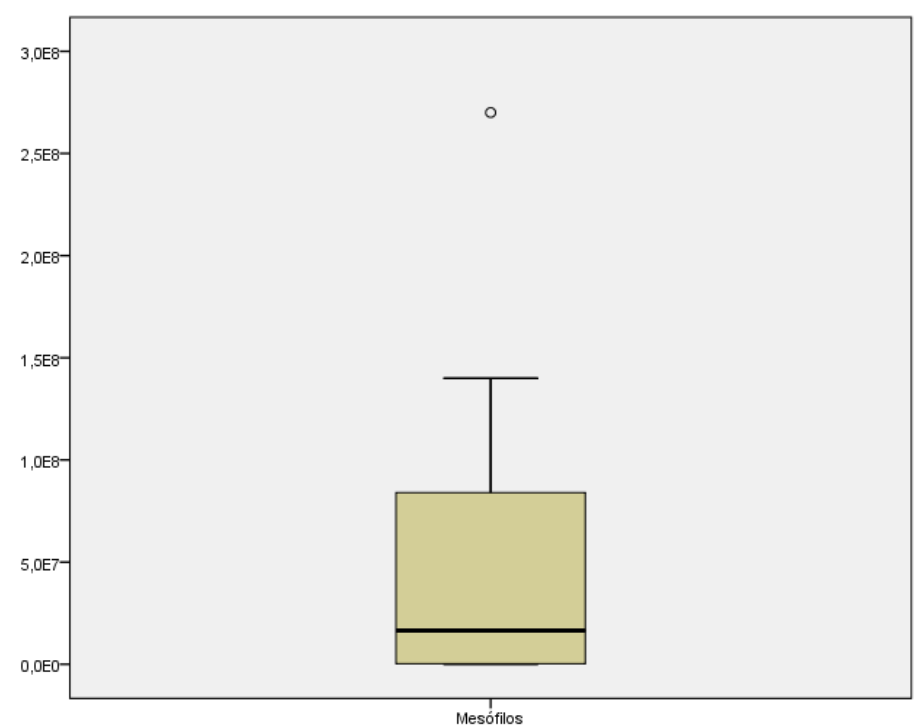

Figura 2. Distribuição da CBHAM em UFC/g quanto à análise das amostras dos três grupos amostrais estudados.

A seguir, na Fig. 3, estão representadas as linhas de crescimento referentes às CBHAP dos três grupos amostrais e, assim como na CBHAM, o grupo controle apresentou um destacado aumento entre os dias sete e 10 , também seguido por uma queda acentuada até o $14^{\circ}$ dia. Só voltou a exibir aumento a partir do $17^{\circ}$ dia, apresentando seu pico no último dia de análise, com máxima de crescimento de $8,9 \times 10^{8} \mathrm{UFC} / \mathrm{g}$. $\mathrm{O}$ grupo irradiado a $0,7 \mathrm{kGy}$ seguia com as contagens mais homogêneas até o $10^{\circ}$ dia, com o maior valor sendo de $1,5 \times 10^{7} \mathrm{UFC} / \mathrm{g}$ no sétimo dia, expressando um relevante aumento entre os dias 10 e 14 , seguido por uma redução até o $21^{\circ}$, quando, então, apresentou o mesmo comportamento do grupo controle, tendo sua reta o ápice no $30^{\circ}$ dia, com a maior contagem sendo $8,4 \times 10^{8} \mathrm{UFC} / \mathrm{g}$. Já o grupo irradiado a $1,0 \mathrm{kGy}$ manteve a homogeneidade do crescimento até o $14^{\circ}$ dia. O restante das análises desse grupo permaneceu sem aumentos ou reduções bruscas, com máxima de $1,2 \times 10^{8} \mathrm{UFC} / \mathrm{g}$ no $17^{\circ} \mathrm{dia}$.

Conforme demonstrado na Fig. 4, na CBHAP as amostras apresentaram valores entre $2,6 \times 10^{2} \mathrm{e}$ $8,9 \times 10^{8} \mathrm{UFC} / \mathrm{g}$, com média de $1,35 \times 10^{8} \mathrm{UFC} / \mathrm{g}$, desvio-padrão de $2,5 \times 10^{8} \mathrm{UFC} / \mathrm{g}$ e mediana de $1,6 \times 10^{7} \mathrm{UFC} / \mathrm{g}$. 
Influência da aplicação...

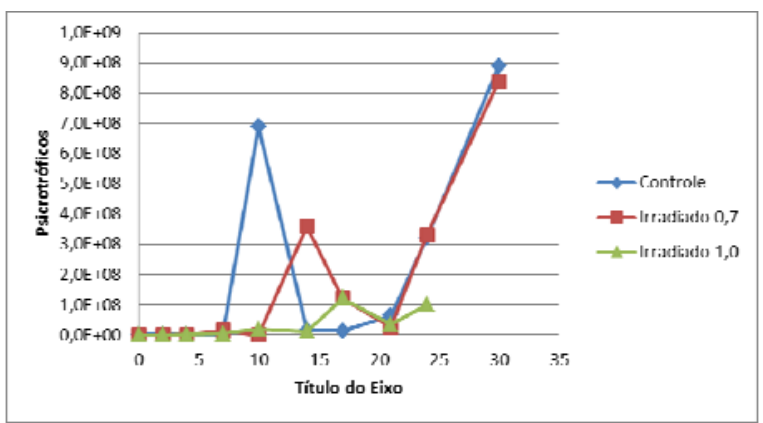

Figura 3. Gráfico em linha comparando a CBHAP em UFC/g dos três grupos analisados.

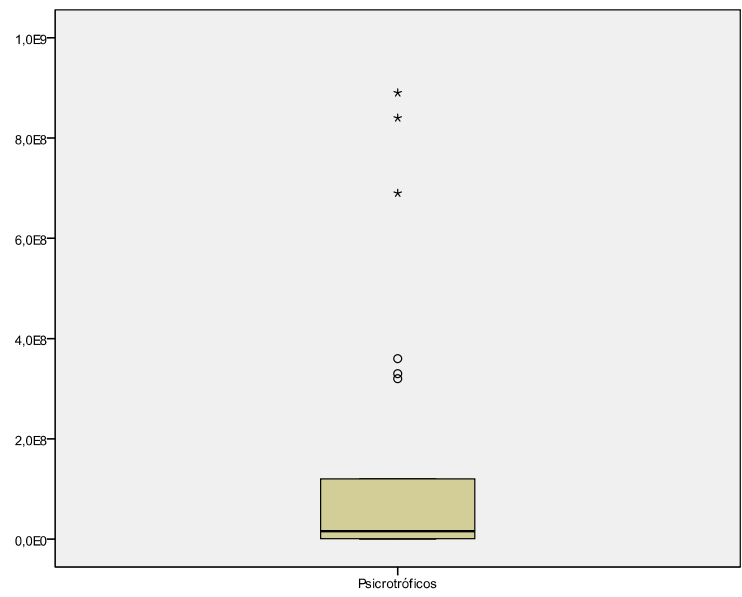

Figura 4. Distribuição da CBHAP em UFC/g quanto à análise das amostras dos três grupos amostrais estudados.

As altas contagens bacterianas iniciais podem estar relacionadas ao fato de os peixes terem sido adquiridos no cais de Itaipu, onde a pesca é realizada, exclusivamente, de forma artesanal. Nesta, são utilizados caícos (pequenas embarcações) sem unidade frigorífica ou sequer recipientes contendo gelo, levando em média de seis a 12 horas, desde a saída até o retorno da embarcação. Dessa forma, os animais permanecem ao sol não só até a chegada à praia, mas também durante a venda, sem contato com gelo em nenhuma dessas etapas do fluxograma. Além disso, no momento da filetagem, pode ocorrer o rompimento de órgãos e vísceras, contaminando a musculatura, que, inicialmente, antes mesmo do abate, encontrava-se estéril. Afinal, como descrito por Prata e Fukuda (2001), as etapas de descamação e evisceração do pescado são importantes estágios da cadeia produtiva, pois deixam a carne ainda mais vulnerável à contaminação bacteriana.
Resultado semelhante foi encontrado por Abreu (2005), em avaliação bacteriológica de peixesapo (Lophius gastrophysus) refrigerado e irradiado, o qual encontrou contagem de microrganismos psicrotróficos correspondente a $7,5 \times 10^{6} \mathrm{UFC} / \mathrm{g}$ no grupo controle, demonstrando que este se apresentava no limite estabelecido pela ICMSF (1986), e redução no dia zero de $6,7 \log$ nas amostras irradiadas a 3,5 e 7kGy. Com base nisso, ao final do experimento, constatou-se o aumento da validade comercial das amostras em todas as doses estudadas, chegando a 18 dias quando submetidas às doses maiores.

Tais contagens também foram estudadas por Soares et al. (2012) para avaliação da eficiência do processo de irradiação, utilizando-se uma fonte de $\mathrm{Cs}^{137}$, em amostras de músculos e gônadas de vieira (Nodipecten nodosus) crus e congelados, submetidos a doses de 2 e $5 \mathrm{kGy}$. Ao 
final do estudo, concluíram que a irradiação foi eficaz somente para o controle de bactérias mesófilas na dose de $5 \mathrm{kGy}$, visto que apenas nesse caso houve diferença estatisticamente significativa quando comparado com o grupo controle. Esse resultado diverge do presente trabalho, no qual não foi encontrada evidência de diferença estatisticamente significativa entre os grupos na $\mathrm{CBHAM}$ e na CBHAP, no entanto foi verificada eficiência da irradiação por feixe de elétrons na diminuição de tais contagens, devido à redução observada no dia zero das análises.

Assim como observado no presente estudo, durante avaliação de pescado fresco comercializado em supermercados na Bahia, Barreto et al. (2012) encontraram elevadas contagens de mesófilos. Altas contagens de ambas as categorias de microrganismos também foram constatadas no estudo bacteriológico realizado por Haida e Muller (1984), em sardinhas (Sardinella aurita) comercializadas em feiras livres, peixarias e supermercados no Paraná.

Santos (2008), após realizar a análise bacteriológica da carne de siri (Callinectes sapidus) pré-cozida, congelada, inspecionada e irradiada com $\mathrm{Co}^{60}$ nas doses de 3 e $5 \mathrm{kGy}$, relatou que houve interferência no crescimento bacteriano em relação à $\mathrm{CBHAP}$, de forma que quanto maior a dose aplicada, maior foi a redução das UFCs, apresentando, quando medidas em $\log _{10}$, uma redução média de $47,9 \%$ na formação de UFCs no grupo de $3 \mathrm{kGy}$ e de $59,4 \%$ no grupo de $5 \mathrm{kGy}$. Contudo, no caso das mesófilas, não foi encontrada diferença estatística significativa, quando comparados o grupo controle com os irradiados em ambas as doses.

Como na legislação nacional vigente, exibida em Brasil (2001), não consta limite para NMP de Enterococccus spp., levou-se em consideração o exposto no Anexo II da RDC n'12/2001: "produto ou lote (se amostra indicativa ou representativa, respectivamente) impróprio para o consumo humano por apresentar microrganismo patogênico ou toxina que representa perigo severo à saúde do consumidor".

Comparando os resultados das enumerações das amostras dos três grupos, não houve evidência de diferença estatisticamente significativa $(\mathrm{P}=$ 0,201).

Pelos resultados exibidos no presente trabalho, após a enumeração de Enterococcus spp., observou-se que, apesar da redução identificada no dia zero, quando comparados o grupo controle aos irradiados a ambas as doses, todas as três amostras iniciais eram positivas em relação à presença desse microrganismo. Além disso, mesmo sendo constatada uma oscilação de um dia para o outro durante a avaliação, considerouse que a irradiação foi eficaz na diminuição da carga bacteriana, uma vez que, no $21^{\circ}$ dia, a amostra do grupo controle encontrava-se com NMP igual a zero e, no $30^{\circ}$ dia, as amostras irradiadas estavam com esse mesmo valor.

Nos traçados individuais referentes às enumerações de Enterococcus spp. dos grupos avaliados, o grupo controle foi o que mais destoou do restante, estando o maior NMP no dia zero da análise, com valor de $2,4 \times 10^{4}$, seguido por um abrupto declínio até o segundo dia de análise, com NMP de 4,6 x 10². Desde então, até o $10^{\circ}$ dia, ocorreu progressivo aumento, quando finalmente atingiu estabilidade em um patamar e permaneceu até o $17^{\circ}$ sem alterações, alcançando o declínio no $21^{\circ}$ dia e mantendo um NMP baixo até o $30^{\circ}$, com mínimo de $<3$ ou igual a zero e máximo de 2,3 x 10. Quanto aos grupos irradiados, ambos apresentaram números mais baixos, sendo os mais altos valores verificados no dia zero, com NMP de $2,4 \times 10^{3}$ no irradiado com a menor dose, e de $1,1 \times 10^{3}$ no irradiado a $1,0 \mathrm{kGy}$, e o menor NMP foi de $<3$ ou igual a zero, no último dia de análise para os dois grupos (Fig. 5).

$\mathrm{Na}$ Fig. 6, visualiza-se que no NMP de Enterococcus spp., a variação foi de zero a $2,4 \mathrm{x}$ $10^{4} \mathrm{UFC} / \mathrm{g}$, com média de $1,52 \times 10^{3} \mathrm{UFC} / \mathrm{g}$, desvio-padrão de $4,45 \times 10^{3} \mathrm{UFC} / \mathrm{g}$ e mediana de $9,3 \times 10 \mathrm{UFC} / \mathrm{g}$. 
Influência da aplicação...

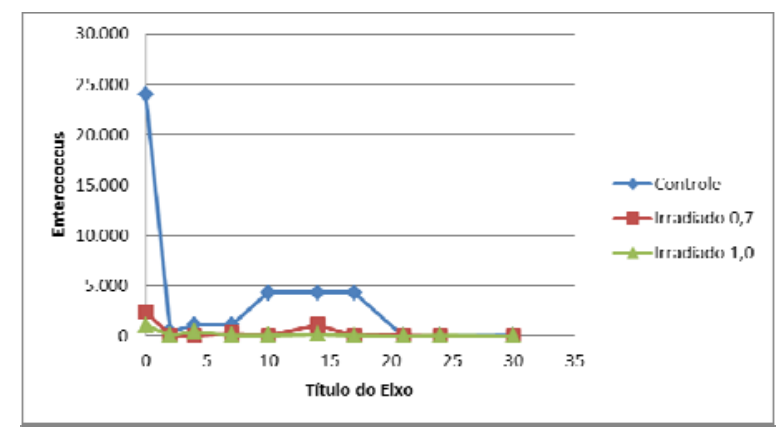

Figura 5. Gráfico em linha comparando a enumeração de Enterococcus spp. em UFC/g dos três grupos analisados.

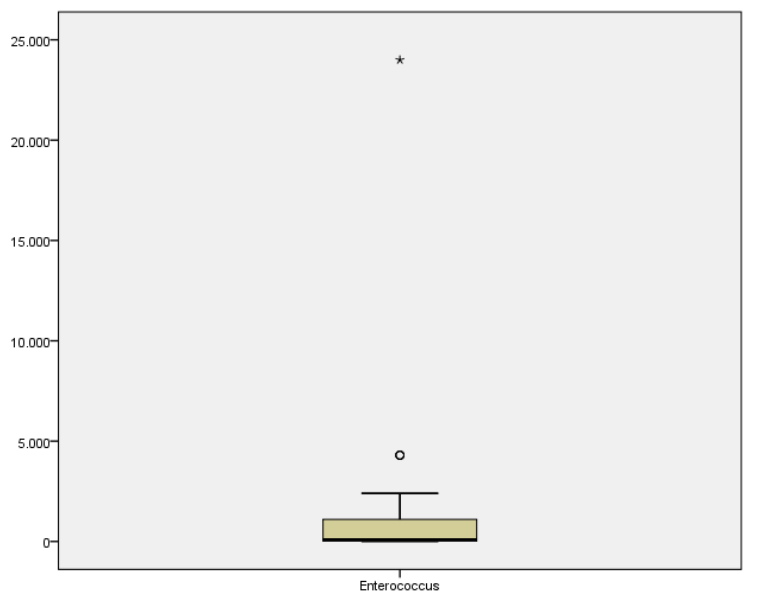

Figura 6. Distribuição da enumeração de Enterococcus spp. em UFC/g quanto à análise das amostras dos três grupos amostrais estudados.

Assim como foi ressaltado nas contagens das bactérias mesófilas e das psicrotróficas, também deve ser levada em conta a modalidade de pesca para captura do pescado avaliado. Além disso, é preciso considerar as condições higiênicosanitárias dos barcos, de descamação, evisceração e filetagem, no que diz respeito às instalações físicas e à qualidade da água utilizada para limpar a bancada, as facas e as mãos do manipulador, associadas à ausência de refrigeração nas primeiras etapas da cadeia produtiva, que podem ter contribuído para os elevados NMP de Enteroccoccus spp. encontrados nas análises iniciais.

Similarmente, Santos (2008), após enumeração de Enterococcus spp. em carne de siri (Callinectes sapidus) pré-cozida, congelada, inspecionada e irradiada com $\mathrm{Co}^{60}$, identificou uma redução de 1,3 ciclo $\log$ e 1,2 ciclo $\log$, respectivamente, nas amostras irradiadas a $3,0 \mathrm{kGy}$ e $5,0 \mathrm{kGy}$, quando comparadas com as do grupo controle. No entanto, essa diminuição não foi suficiente para estabelecer uma diferença estatisticamente significativa. Em investigação bacteriológica em mexilhões (Perna perna) précozidos, congelados e irradiados com $\mathrm{Co}^{60}$, Valente (2004) descreveu que as doses de $3 \mathrm{e}$ $5 \mathrm{kGy}$ foram suficientes para redução do número de Enterococcus spp. quando essas amostras foram comparadas com a amostra controle, enquanto no grupo irradiado a $7 \mathrm{kGy}$ ocorreu ausência desse microrganismo.

Mesmo que esses microrganismos não sejam considerados os melhores indicadores de contaminação fecal, uma enumeração alta deles em uma matriz alimentícia que não os contenha originalmente em sua formulação aponta a adoção de insuficientes medidas sanitárias, de 
conservação e manutenção do alimento, o que permite a proliferação desses e de outros microrganismos patógenos ou deteriorantes (Franco e Landgraf, 2008). Assim, considera-se que as amostras analisadas, as quais continham essa bactéria, constituíam risco à saúde do consumidor.

\section{CONCLUSÕES}

Com base na análise dos resultados encontrados, conclui-se que a irradiação por feixe de elétrons, quando aplicada em filés de corvina refrigerados, nas doses de 0,7 e 1,0kGy, age de forma eficaz na redução da CBHAM, da CBHAP e do NMP de Enterococcus spp., presentes inicialmente na matriz estudada. No entanto, no presente trabalho, não foi detectada diferença estatisticamente significativa $(\mathrm{P}>0,05)$ entre os três grupos em nenhuma das contagens e enumeração estudadas.

\section{REFERÊNCIAS}

ABREU, M.G. Caracterização sensorial e análise bacteriológica do peixe-sapo (Lophius gastrophysus) refrigerado e irradiado. 2005. 90f. Dissertação (Mestrado em Medicina Veterinária) - Programa de Pós-graduação em Medicina Veterinária, Universidade Federal Fluminense, Niterói, RJ.

BARRETO, N.S.E.; MOURA, F.C.M.; TEIXEIRA, J.A. et al. Avaliação das condições higiênicosanitárias do pescado comercializado no município de Cruz das Almas, Bahia. Rev. Caatinga, v.25, p.86-95, 2012.

BRASIL. Ministério da Saúde. Agência Nacional de Vigilância Sanitária - ANVISA. Resolução da Diretoria Colegiada (RDC) $\mathrm{n}^{\mathrm{o}} 12$, de 02 de janeiro de 2001. Aprova o regulamento sobre padrões microbiológicos para alimentos e seus anexos I e II. Diário Oficial [da] União, Brasília, DF, 10 jan. 2001. Seção 1.

DOWNES, P.F.; ITO, K. Compendium of methods for the microbiological examination of foods. 40.ed. Washington: APHA, 2001. $676 \mathrm{p}$.

FELLOWS, P.J. Tecnologia do processamento de alimentos: princípios e prática. 2.ed. Porto Alegre: Artmed, 2006. 602 p.

FIPERJ. FUNDAÇÃO INSTITUTO DE PESCA DO ESTADO DO RIO DE JANEIRO. Relatório 2011. Disponível em: <http://www.fiperj.rj.gov.br/ fiperj_imagens/arquivos/revistarelatorios2011.pdf $>$.

Acessado em: 8 Jul. 2013.
FRANCO, B.D.G.M.; LANDGRAF, M. Microbiologia dos alimentos. São Paulo: Ed. Atheneu, 2008. $182 \mathrm{p}$.

GIRAFFA, G.; OLIVARI, A.M.; NEVIANI, E. Isolation of vancomycin-resistant Enterococcus faecium from Italian cheeses. Food Microbiol., v.17, p.671-677, 2000.

HAIDA, K.S.; MULLER, E.E. Estudo bacteriológico da sardinha (Sardinella aurita) comercializada em Londrina, Paraná. Semina: Ciênc. Agr., v.5, p.53-56, 1984.

JAY, J.M. Microbiologia de alimentos. 6.ed. Porto Alegre: Artmed, 2005. $711 \mathrm{p}$.

MERCK microbiology manual. Darmstadt, Germany: Merck, 1996. 405 p.

PRATA, L.F.; FUKUDA, R.T. Fundamentos de higiene e inspeção de carnes. Jaboticabal, São Paulo: FUNEP, 2001. 349 p.

RIEDEL, G. Controle sanitário dos alimentos. 3.ed. São Paulo: Editora Atheneu, 2005. 455 p.

SAMPLING for microbiological analysis: principles and specific applications. In: _. Microorganisms in food. 2.ed. Nova Iorque: University of Toronto Press, 1986.

SANTOS, E.B. Eficiência da radiação gama sobre a carga bacteriana da carne de siri (Callinectes sapidus) pré-cozida, congelada, inspecionada $e$ irradiada. 2008. 57f. Monografia (Especialização em Irradiação de Alimentos) - Curso de Especialização em Irradiação de Alimentos, Universidade Federal Fluminense, Niterói, RJ.

SOARES, I.C.; MESQUITA, E.F.M.; FRANCO, R.M. et al. Análise bacteriológica de músculo e gônadas de vieira, Nodipecten nodosus (Mollusca: Bivalvia), congelados e irradiados. Braz. J. Vet. Res. Anim. Sci., v.49, p.24-29, 2012.

SPECIES fact sheets. Micropogonias furnieri. [s.1.]: Fisheries and Aquaculture Department, 2013. Disponível em: <http://www.fao.org/fishery/ species/2351/en>. Acessado em: 9 fev. 2013.

VALENTE, A. M. Efeito da irradiação sobre mexilhões [Perna perna (Linnaeus, 1758)]: coliformes termotolerantes e enterococcus; ação antimicrobiana e análise sensorial das amostras. Niterói, 2004. 85f. Dissertação (Mestrado em Medicina Veterinária) Programa de Pós-graduação em Medicina Veterinária, Universidade Federal Fluminense, Niterói. RJ. 